http://dx.doi.org/10.11606/issn.2238-6149.v26i3pi

\title{
Terapia Ocupacional Psicossocial: avanços na pesquisa
}

Apresentamos aos leitores mais um fascículo da Revista de Terapia Ocupacional da USP. Os artigos publicados refletem avanços na pesquisa e produção de conhecimento na área, resultados de esforços de pesquisadores engajados no ensino de graduação e pós-graduação. Salienta-se a emergência de novos objetos de estudo e a qualificação dos métodos e estratégias de pesquisa adotados.

Destacamos a produção de trabalhos na área da Saúde Mental e suas interfaces, que atestam a importância da centralidade da área na própria constituição do campo da Terapia Ocupacional na atualidade, além da capacidade de construir e disseminar conceitos e estratégias de manejo orientadas pela abordagem psicossocial para as demais áreas da profissão.

Mostram também que o modelo psicossocial se constrói passo a passo e isso se expressa nas características do trabalho dos serviços e suas equipes. Nesse sentido, os estudos qualitativos e relatos de experiência contribuem para apoiar e desenvolver esse modelo.

Os estudos têm buscado confirmar as evidências das novas práticas e em especial, as formas de pesquisar, pensar e ensinar nesse campo. Também deixam claro as implicações e forte vinculação entre a Terapia Ocupacional e o modelo psicossocial, o que nos permite hoje no Brasil afirmar a emergência da Terapia Ocupacional psicossocial, não como uma aposta no futuro, mas como uma realidade já vivida no contexto das Redes de Atenção Psicossocial

Os novos referenciais e especialmente aqueles ligados ao desenvolvimento das redes de serviços apontam para importantes mudanças nas orientações da Terapia Ocupacional em Saúde Mental e de toda a equipe de trabalho, que são aqui destacadas:

1.Ações centradas na pessoa, em seu contexto e de acordo com suas necessidades;

2.Foco no empoderamento, na participação e na defesa dos direitos de cidadania dos usuários;

3.Desenvolvimento do respeito, do direito e do convívio com a diversidade e abandono de rígidos padrões normativos que definem saúde e doença mental;

4.Construção de projetos terapêuticos, singulares, flexíveis, negociados e não vinculados apenas à remissão de sintomas, com estabelecimento de metas significativas construídas e compartilhadas com os usuários;

5.Processo de trabalho em equipe baseado nas múltiplas negociações e construção de parcerias (equipes, serviços e usuários);

6.Desenvolvimento de ações nos territórios de vida e trabalho dos usuários, estabelecimento de parcerias interinstitucionais e abandono da ênfase de tratamentos centrados nos serviços e na oferta de procedimentos técnicos especialísticos;

7.Integração entre as intervenções terapêuticas e sociais e entre os momentos concebidos tradicionalmente em termos de prevenção, tratamento e reabilitação;

8.Foco no fortalecimento da saúde e no desenvolvimento de fatores de proteção e redução de fatores de risco que expõem os usuários a crises e recaídas.

Se pode perceber que a Terapia Ocupacional em Saúde Mental ampliou seus saberes e estratégias de intervenção para a construção de novos referenciais. Esse processo está em curso: somos protagonistas dessas mudanças.

Nesse contexto, se coloca a importância da formação para o trabalho interprofissional articulada necessariamente com a produção de conhecimento capaz de dar suporte, concretizar e criar patamares mais sólidos e evidências que contribuam para o avanço e qualificação do novo modelo assistencial.

O fortalecimento e a integração entre ensino interprofissional e pesquisa, no contexto das novas exigências colocadas pelas Redes de Atenção Psicossocial, são dimensões inseparáveis e devem ser consideradas prioridades operativas para atualidade.

Esperamos que todos os atores envolvidos na construção e fortalecimento da Terapia Ocupacional Psicossocial encontrem aqui boas leituras e novas inspirações!

Elisabete Ferreira Mângia

Melissa Tieko Muramoto 